\title{
Enhanced adsorption of perfluroalkyl substances from aqueous environment using graphene oxide-based magnetic ferrite nanohybrids
}

S.SD. ELANCHEZHIYAN ${ }^{1}$, YEJIN KIM ${ }^{2}$, YEON JI YEA ${ }^{3}$, CHANG MIN PARK ${ }^{4, *}$

Department of Environmental Engineering Kyungpook National University

80 Daehak-ro, Buk-gu, Daegu 41566, Republic of Korea ${ }^{1}$ chezhiyandasarathan@gmail.com; ${ }^{2}$ rysa12@naver.com; ${ }^{3}$ dpduswl@naver.com; ${ }^{4}$ cmpark@knu.ac.kr *Corresponding author: C. M. Park

Perfluorooctanoic acid (PFOA $\mathrm{C}_{7} \mathrm{~F}_{15} \mathrm{COO}^{-}$) and perfluorooctanesulfonic acid (PFOS, $\mathrm{C}_{8} \mathrm{~F}_{17} \mathrm{SO}_{3}{ }^{-}$) are persistent organic contaminants, and they have recently been recognized as emerging contaminants in aquatic environments worldwide because of their effects on human health. Herein, we report the synthesis of graphene oxide (GO) or reduced graphene oxide (rGO) decorated with highly stable lanthanum and zirconium-imprinted manganese ferrites ( $\mathrm{La} / \mathrm{Zr}-\mathrm{MnFe}_{2} \mathrm{O}_{4} @ \mathrm{GO} / \mathrm{rGO}$ ) for the adsorptive removal of PFOA and PFOS. The effective intercalation of magnetic $\mathrm{La} / \mathrm{Zr}-\mathrm{MnFe}_{2} \mathrm{O}_{4}$ into $\mathrm{GO} / \mathrm{rGO}$ was confirmed from FTIR, PXRD, VSM, and Raman spectra. Surface morphologies and particle sizes of as-synthesized adsorbents were determined using FE-SEM, HR-TEM, EDX, and BET analysis. Zeta potential measurements showed that the surface charge of $\mathrm{GO} / \mathrm{rGO}$ changed significantly after intercalation with $\mathrm{La} / \mathrm{Zr}$ $\mathrm{MnFe}_{2} \mathrm{O}_{4}$ nanoparticles under ultrasonication. The adsorption capacities of bare $\mathrm{La} / \mathrm{Zr}-\mathrm{MnFe}_{2} \mathrm{O}_{4}$ and the $\mathrm{La} / \mathrm{Zr}-$ $\mathrm{MnFe}_{2} \mathrm{O}_{4} @ \mathrm{GO} / \mathrm{rGO}$ nanohybrids for the removal of PFOA and PFOS molecules were separately examined. Several factors such as the contact time, $\mathrm{pH}$, initial concentration of PFOA/PFOS, type of coexisting anions, and presence of other organic compounds were optimized to determine the maximum density of the prepared adsorbents. The adsorption of PFOA and PFOS on the $\mathrm{La} / \mathrm{Zr}-\mathrm{MnFe}_{2} \mathrm{O}_{4} @ \mathrm{GO} / \mathrm{rGO}$ nanohybrids was governed mainly by electrostatic attraction followed by hydrophobic interaction and hydrogen bonding, as evidenced by various spectro-analytical techniques, including FTIR, XPS, and SEM/TEM-EDX. Kinetic and isotherm experiments indicated that the adsorption system followed the pseudo-second-order and Langmuir isotherm models, respectively. The $\mathrm{La} / \mathrm{Zr}-\mathrm{MnFe}_{2} \mathrm{O}_{4} @ \mathrm{GO} / \mathrm{rGO}$ nanohybrids are potential candidates for the removal of PFOA and PFOS from water and wastewater. 